\title{
The impact of servitization of manufacturing on the human capital
}

\author{
LiXian Chen ${ }^{1}$ \\ ${ }^{1}$ School of Economics and trade, Guangdong University of Foreign Studies, GuangZhou, China
}

\begin{abstract}
This paper uses the PSM-DID method to investigate the impact of servitization of manufacturing on enterprises' human capital based on Chinese listed manufacturing corporations' financial data. The empirical results show that servitization of manufacturing has a negative impact on the proportion of production and sales personnel, but has a positive influence on the proportion of technical personnel and highly educated personnel, which both by increasing path variables productivity and capital-intensity.
\end{abstract}

\section{Introduction}

As the world economy and technologies are progressing, market demand has shifted from manufactured goods to integrated solutions, customized service, product life-cycle management and intellectualized service[1]. For instance, Rolls- Royce itself is the manufacturing company and several specialists for the installation, repair, and maintenance of engines such as Lufthansa Technik form the service providers[2]. And now, how to define the connotation of servitization of manufacturing, adopt scientific methods to measure it, and analyze its impact on various aspects of the economy are an important topic in academic research. When it comes to our topic, whether servitization will have a positive effect on the human capital, the study of this problem is helpful to put forward constructive suggestions for the coordinated development of industrial structure adjustment and human capital accumulation.

\section{Data and Variables}

\subsection{Data}

we choose the listed manufacturing companies in China between 2011 and 2018 as our study material. In order to construct panel data for empirical study, we made a preliminary selection of all the manufacturing enterprises, the principles of selection are as follows: firstly, to ensure that the sample enterprises have at least two years of listing experience and have relatively stable operation, so excluding companies listed after December 31, 2013; secondly, to make sure the continuous availability of sample data, so excluding companies that went bankrupt or failed, or with missing or incomplete data, or belonging to ST, ST* and PT between 2011 and 2018. Our data is mainly from the WIND database, and lastly combined with the sample enterprise website and enterprise annual report to supplement and verify the missing data.

\subsection{Variables}

- Human capital. The proportion of technical personnel is refer to the number of technical staff in the ratio of the total number of employees; the proportion of highly educated personnel is mean that the university degree and above in proportion to the total number of employees; production and sales personnel ratio is refer to the number of production and sales staff in the proportion of the total number of employees.

- Servitization of manufacturing. The first step is by viewing the name of business products, the types of business product, business scope and other information, to judge whether the manufacturing enterprise whether carries out service business[3]. Next, according to the company's annual report, checking the composition of operating income, and manually collect service revenue data for each manufacturing enterprise. Lastly, the main business income of manufacturing enterprises is divided into two parts: service business income and non-service business income. On the one hand, dummy variables are used to qualitatively judge whether an enterprise has service business (SER) or not. On the other hand, the degree of servitization is defined according to the proportion of service business revenue to the total revenue (SER-Ratio).

- Path variables. We postulate that servitization of manufacturing influences human capital development through two paths, namely, the promotion of total factor productivity (tfp) and improvement in capital-intensity (ins). (1) Total factor productivity refers to the ratio of total output to input factors. (2) Capital-intensity means fixed assets as a proportion of the workforce.

- Control variables. The age of firm (age) is calculated as the year of 2018 minus the year of establishment; Enterprise scale (size) is expressed 
as the natural logarithm of total assets; Corporate revenue (roa) is referred to the rate of return on total assets; Corporate liabilities (debt) are expressed by the asset-liability ratio; Capital factor scale (cap) means that the natural logarithm of the average annual balance of net fixed assets; Labor factor scale (lab) has the meaning of the logarithm of the payable employees' wages and salaries

\section{Research Method}

\subsection{Econometric Model}

To investigate the influence of servitization on enterprise's human capital, we construct "counterfactual" by means of propensity score matching (PSM) and estimate it by difference-in-differences (DID) method[4]. Accordingly, we first identify the probability of being servitization using a logit model:

$\log i t\left(S E R_{i t}=1\right)=\phi\left(X_{i t}\right)$

$S E R_{i t}$ is refer to servitization firms $\mathrm{i}$ at time period $\mathrm{t}$, where $\mathrm{X}$ is a vector of covariates observed in the time period before servitization. The choice of covariates is influenced by the empirical literature on servitization[5], this vector consists of the pre-servitization levels of return on assets, gross revenue, fixed assets, asset-liability ratio.

Now let $p_{i}$ denote the predicted probability of being servitization for plant $\mathrm{i}$ in the group of servitization plants

(say group A) and let $p_{j}$ denote the predicted probability of being servitization for plant $\mathrm{j}$ in the control group (say group B). A standard matching estimator of the causal effect of servitization can be written as:

$$
u=\sum_{i \in A}\left(y_{i}-\sum_{j \in B} g\left(p_{i}, p_{j}\right) y_{j}\right)
$$

Let $y_{i}\left(y_{j}\right)$ be human capital of firms $\mathrm{i}(\mathrm{j})$, where $g($.$) is a function assigning the weights to be placed on$ the comparison firm $\mathrm{j}$ while constructing the counterfactual for servitization firm i. Comparing several algorithms we found rather consistent results, yet we decided for a 2nearest neighbour (NN) matching because it showed the best balancing properties of control variables.

Based on the matching results, $S E R_{i}$ is a binary indicator that equals 1 if servitization of manufacturing and 0 otherwise, Year $r_{i}$ is also a binary indicator that equals 1 is represented enterprises have implemented the servitization and 0 otherwise. humit is human capital of firm $\mathrm{i}$ at time period $\mathrm{t}$, Where $\Delta h u m_{i}^{1}\left(\Delta h u m_{i}^{0}\right)$ is the difference in human capital between the two time points examined by the treatment group (the control group). According to DID, the change of human capital after enterprise servitization can be expressed as:

$$
\begin{gathered}
\sigma=E\left(\sigma_{i} \mid S E R_{i}=1\right)=E\left(\Delta h u m_{i}^{1} \mid S E R_{i}=1\right)-E\left(\Delta h u m_{i}^{0} \mid S E R_{i}=1\right) \\
\text { In practice, we can only compute }
\end{gathered}
$$

$E\left(\Delta h u m_{i}^{0} \mid S E R_{i}=0\right)$ thus, the solution is to replace the unobservable $E\left(\Delta h u m_{i}^{0} \mid S E R_{i}=1\right)$ with the observable $E\left(\Delta h u m_{i}^{0} \mid S E R_{i}=0\right)$

Hence,

$$
\sigma=E\left(\sigma_{i} \mid S E R_{i}=1\right)=E\left(\Delta h u m_{i}^{1} \mid S E R_{i}=1\right)-E\left(\Delta h u m_{i}^{0} \mid S E R_{i}=0\right)
$$

After the above settings, we could get the following equation of estimation by difference-in-differences method. hum $_{i j t}=\alpha_{0}+\alpha_{1} S E R_{i}+\alpha_{2}$ Year $_{t}+\alpha_{3}$ SER $_{i}^{*}$ Year $_{t}+X_{i t}^{\prime} \beta+\gamma_{\kappa}+\varepsilon_{i j t}$ (5)

In equation (5), $\alpha_{3}$ is the core coefficient of this paper, the positive and negative mean the increase or decrease of human capital after the servitization of enterprises. $X_{i t}^{\prime}$ represent the control variables at the enterprise level, $\gamma_{\kappa}$ and $\varepsilon_{i j t}$ represent fixed effects and random terms respectively.

Next, our paper examine the transmission mechanism about which servitization of manufacturing affects enterprises' human capital, we use the mediation effect model to perform the following regression: hum $_{i j t}=\alpha_{0}+\alpha_{1}$ SER $_{i}+\alpha_{2}$ Year $_{t}+\alpha_{3}$ SER $_{i}^{*}$ Year $_{t}+X_{i t}^{\prime} \beta+\gamma_{\kappa}+\varepsilon_{i j t}$ (6) $N_{i j t}=b_{0}+b_{1} S E R_{i}+b_{2}$ Year $_{t}+b_{3}$ SER $_{i} *$ Year $_{t}+X_{i t}^{\prime} \beta+\gamma_{\kappa}+\varepsilon_{i j t}$ (7) hum $_{i j t}=c_{0}+c_{1} S E R_{i}+c_{2}$ Year $_{t}+c_{3} S R_{i} *$ Year $_{t}+\phi N_{i j t}+X_{i t}^{\prime} \beta+\gamma_{\kappa}+\varepsilon_{i j t}$ (8)

In this formula, $\mathrm{N}$ is the path variable, which includes the following two variables: total factor productivity (tfp) and capital-intensity (ins). If the influence of path variable on enterprises' human capital is positive, we have the coefficients of interaction terms $\alpha_{3}$ is larger than $c_{3}$; If the path variable is negatively correlated with enterprises' human capital, we have the coefficients of interaction terms $\alpha_{3}$ is less than $c_{3}$.

\subsection{Endogenous Problem}

In order to eliminate the interference of endogenous problems in this study, and to ensure the accuracy and reliability of the estimation results of DID method, we plot, in figure1, time trend of human capital (measured by the proportion of production and sales personnel) for servitization (treatment group) and non-servitization (control group). Taking starting servitization in 2015 as an example, it is clear that before 2015 , the two groups have quite similar trends.

This parallel pretreatment trend in human capital between treatment and control groups alleviates the concern that our treatment and control groups are ex ante incomparable, which leads support to the satisfaction of our DID identifying assumption. Meanwhile, there is visible divergence in trends of human capital after 2015, when enterprises started to servitization. Therefore, the inconsistency in timing between the divergence in human capital and servitization after 2015 which suggests that 
servitization of manufacturing can effectively influence human capital.

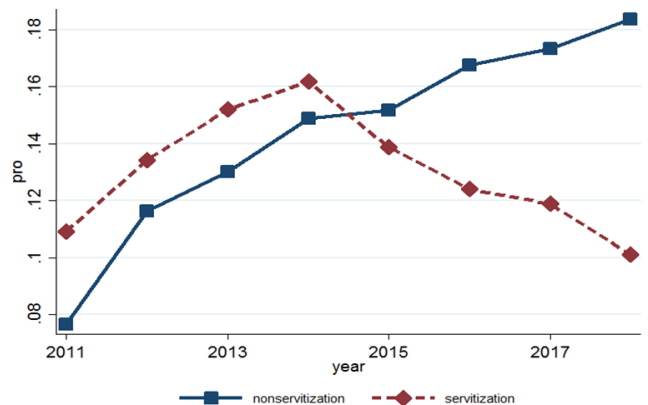

Fig1. Changes of Human Capital for Servitization VS NonServitization

\section{Empirical Results and Explanation}

\subsection{Baseline Regression}

Table 1 presents the estimation results from Equation (5). Column (1) reports the fixed-effects estimation which taking the proportion of production and sales personnel (pro) as the dependent variable. After adding a series of control variables and fixed effects, we can find that the estimated coefficient of SER*Year is negative and statistically significant at the 1-percent level, which provides empirical evidence that servitization reduce the ratio of production and sales personnel of enterprises.

Column (2) run a regression using the method of PSMDID are taking the proportion of technical personnel (tec) as the dependent variable, column (3) are taking the proportion of highly educated personnel (edu) as the dependent variable, which they all taking SER*Year variables as the independent variables, various features of the firms as control variables, and including a series of fixed effects. The result shows that the estimated coefficients of core variables are positive and significant in both the ordinary least squares estimation and fixedeffects estimation, which reveals the importance of servitization in the growth of technical personnel ratio and the proportion of highly educated people within enterprises.

Table1. Servitization of Manufacturing and Human Capital

\begin{tabular}{|c|c|c|c|}
\hline & pro & tec & edu \\
\hline SER*Year & $\begin{array}{c}-2.7632 * * * \\
(0.4154)\end{array}$ & $\begin{array}{c}0.9092^{* * *} \\
(0.2675)\end{array}$ & $\begin{array}{c}0.8769^{* * *} \\
(0.3307)\end{array}$ \\
\hline control variable & yes & yes & yes \\
\hline year fixed effect & yes & yes & yes \\
\hline industry fixed effect & yes & yes & yes \\
\hline province fixed effect & yes & yes & yes \\
\hline ownership fixed effect & yes & yes & yes \\
\hline $\mathrm{R}^{2}$ & 0.2030 & 0.2365 & 0.2489 \\
\hline observations & 9548 & 9141 & 9548 \\
\hline
\end{tabular}

a. In brackets is the standard error for clustering to an enterprise. $* * *, * *, *$ represent significance at 1,5 and 10 percent, respectively. The following tables are the same.

\subsection{Evaluation of the Transmission Mechanism}

The results are listed in table 2 and table 3 , table 2 reports the total factor productivity effect, table 3 reports the capital-intensity effect.

In terms of the effect of total factor productivity, column (1) shows that the servitization have significantly improved the productivity of firms. Firstly, compare the estimated coefficients of SER*Year for column (1) of table 1 with those for column (2) of table 2 , it's obviously that 2.6654 is larger than -2.7632 , so we can make a conclusion that the effect of productivity on the ratio of production and sales personnel is negative and significant. Secondly, compare the estimated coefficients of SER*Year for column (2) of table 1 with those for column (3) of table 2, which indicated that 0.9023 in table 2 is smaller than 0.9092 in table 1. Therefore, based on controlling a series of firm's characteristics and fixed effects, we can confirm that productivity have a positive effect on the growth of technical personnel ratio. Thirdly, compare the estimated coefficients of SER*Year for column (3) of table 1 with those for column (4) of table 2, we also can find that 0.8769 is bigger than 0.8680 , which represent that productivity really promoted the growth of proportion of highly educated people.

When it comes to the effect of capital-intensity, column (1) revealed that the servitization has a statistically significant positive impact on capital-intensity, which implies that with the degree of servitization is improved, capital-intensity within firms will be enhanced. At the beginning, compare the estimated coefficients of SER*Year for column (1) of table 1 with those for column (2) of table 3, the estimated coefficients in table $3(-2.7632)$ is smaller than table $4(-2.5811)$, which is similar with the effect of total factor productivity. As a result, we also can said that the effect of capital-intensity on the ratio of production and sales personnel is negative and significant. Next, compare the estimated coefficients of SER*Year for column (2) of table 1 with those for column (3) of table 3, it's obviously that 0.9092 in table 1 is larger than 0.8877 in table 3 , so the effect of capital-intensity on the ratio of technical personnel is positive and significant. Lastly, compare the estimated coefficients of SER*Year for column (3) of table 1 with those for column (4) of table 3, it's also that 0.8769 in table 1 is larger than 0.7896 in table 3 , we can make a conclusion that capital-intensity have promoted the growth of proportion of highly educated people.

Table2. Estimation Results of TFP

\begin{tabular}{|c|c|c|c|c|}
\hline & TFP & pro & tec & edu \\
\hline SER*Year & $\begin{array}{l}4.6775 * * \\
(2.3325)\end{array}$ & $\begin{array}{c}- \\
2.6654 * * * \\
(0.4123) \\
\end{array}$ & $\begin{array}{c}0.9023 * * * \\
(0.2673)\end{array}$ & $\begin{array}{c}0.8680 * * * \\
(0.3302)\end{array}$ \\
\hline tfp & & $\begin{array}{c}- \\
0.0070 * * * \\
(0.0016)\end{array}$ & $\begin{array}{l}-0.0006 \\
(0.0008)\end{array}$ & $\begin{array}{c}0.0075 * * * \\
(0.0017)\end{array}$ \\
\hline $\begin{array}{c}\text { control } \\
\text { variable }\end{array}$ & yes & yes & yes & yes \\
\hline fixed effect & yes & yes & yes & yes \\
\hline $\mathrm{R} 2$ & 0.6046 & 0.2033 & 0.2365 & 0.2514 \\
\hline observations & 9514 & 9548 & 9141 & 9548 \\
\hline
\end{tabular}


Table3. Estimation Results of TFP

\begin{tabular}{|c|c|c|c|c|}
\hline & ins & pro & tec & edu \\
\hline SER*Year & $0.0156^{*}$ & - & $0.8877^{* * *}$ & $0.7896^{* *}$ \\
& $(0.0089)$ & $\begin{array}{c}2.5811^{* * *} \\
(0.4106)\end{array}$ & $\begin{array}{c}(0.2677) \\
(0.3290)\end{array}$ \\
\hline ins & & $\begin{array}{c}5.0692^{* * *} \\
(0.6719)\end{array}$ & $\begin{array}{c}1.2365^{* * *} \\
(0.4462)\end{array}$ & $\begin{array}{c}4.8657^{* * *} \\
(0.4625)\end{array}$ \\
\hline $\begin{array}{c}\text { control } \\
\text { variable }\end{array}$ & yes & yes & yes & yes \\
\hline fixed effect & yes & yes & yes & yes \\
\hline $\mathrm{R}^{2}$ & 0.4105 & 0.2122 & 0.2381 & 0.2640 \\
\hline observations & 9514 & 9548 & 9141 & 9548 \\
\hline \multicolumn{5}{|r|}{} \\
\hline
\end{tabular}

\subsection{Robustness Check}

In the robustness check, we run a regression using probit model taking servitization of manufacturing as the independent variables, the regression results are reported in table 4. The results show that the direction and significance of the estimated coefficient of servitization as a core explanatory variables did not change. It indicates that the regression results of servitization of manufacturing and human capital are robust.

Table4. Robustness Check Estimation Results of Servitization and Human Capital

\begin{tabular}{|c|c|c|c|}
\hline & pro & tec & edu \\
\hline SER & $\begin{array}{c}-2.7307^{* * *} \\
(0.3538)\end{array}$ & $\begin{array}{c}0.7118^{* * *} \\
(0.2356)\end{array}$ & $\begin{array}{c}0.7896^{* *} \\
(0.2861)\end{array}$ \\
\hline control variable & yes & yes & yes \\
\hline fixed effect & yes & yes & yes \\
\hline $\mathrm{R}^{2}$ & 0.2111 & 0.2369 & 0.2670 \\
\hline observations & 12824 & 12283 & 12824 \\
\hline
\end{tabular}

Further, we use the degree of servitization of manufacturing as the independent variables, and taking the ordinary least squares estimation and the fixed-effects estimation to regression analysis. We can find that the regression results (table 4) were basically consistent with table 1. That is to say, the servitization of manufacturing significantly reduces the proportion of production and sales personnel, significantly increases the proportion of technical personnel and highly educated personnel.

Table5. Robustness Check Estimation Results of the Degree of Servitization and Human Capital

\begin{tabular}{|c|c|c|c|}
\hline & pro & tec & edu \\
\hline SER_Ratio & $\begin{array}{c}-0.1158^{* * *} \\
(0.0104)\end{array}$ & $\begin{array}{c}0.0281^{* * *} \\
(0.0077)\end{array}$ & $\begin{array}{c}0.0326^{* * *} \\
(0.0086)\end{array}$ \\
\hline control variable & yes & yes & yes \\
\hline fixed effect & yes & yes & yes \\
\hline $\mathrm{R}^{2}$ & 0.5175 & 0.2336 & 0.3056 \\
\hline observations & 14549 & 12779 & 14549 \\
\hline
\end{tabular}

\section{Conclusion and Policy Implications}

As a result, the main purpose of this study was to empirically investigate the influence of servitization on enterprises' human capital, which using a panel dataset covering manufacturing listed company over the period 2011-2018. The study finds that servitization of manufacturing has a negative and significant impact on the ratio of production and sales personnel. By contrast, we find that servitization of manufacturing has a positive and significant impact on the proportion of technical personnel and highly educated personnel in enterprises. This paper further analyzes the transmission mechanism of servitization affecting human capital by using the mediation effect model, including the effect of total factor productivity and capital-intensity. The result shows that both productivity and capital-intensity has a negative effect on the ratio of production and sales personnel, but both productivity and capital-intensity have a positive impact on the proportion of technical personnel and highly educated personnel.

The findings of this study imply that servitization of manufacturing helps reduce low-end labor force and increase high-end labor force by increasing productivity and changing capital intensity. Therefore, the government should actively encourage manufacturing enterprises to carry out servitization of manufacturing, which is conducive to promoting enterprise transformation and upgrading on the one hand, and improving the labor structure of China on the other hand.

\section{Acknowledgment}

MOE (Ministry of Education in China) Project of Humanities and Social Sciences (Project No.20YJC790010).

\section{References}

1. S. S. Ali, F. T. Madaan, S. Chan, and S. Kannan, "Inventory management of perishable products: a time decay linked logistic approach," International Journal of Production Research, 2013, Vol.51, No.13, pp.3864-3879.

2. H. Gebauer, M. Paiola, and N. Saccani, "Characterizing service networks for moving from products to solutions," Industrial Marketing Management, 2013, Vol.42, No.1, pp.31-46.

3. E. Fang, R. W. Palmatier, and J. B. E. M. Steenkamp, "Effect of service transition strategies on firm value," Journal of Marketing, 2008, Vol.72, No.5, pp.1-14.

4. P. R. Rosenbaum, and D. B. Rubin, "The central role of the propensity score in observational studies for causal effects," Biometrika, 1983, Vol.70, No.1, pp.41-55.

5. C. Kowalkowski, H. Gebauer, B. Kamp, "Servitization and deservitization: Overview, concepts, and definitions," Industrial Marketing Management, 2017, Vol.60, pp.4-10. 